\title{
DESA CANGGU, BALI SEBUAH BASECAMP BAGI DIGITAL NOMAD? IDENTIFIKASI PRODUK WISATA BERDASARKAN 4 A (ATTRACTION, AMENITY, ACCESSIBILITY, ANCILLIARY) Canggu, Bali Is A Basecamp for Digital Nomad? Identification of Tourism Products Based 4 A (Attraction, Amenity, Accessibility, Ancilliary)
}

\author{
Ni Putu Diah Prabawati \\ Politeknik Pariwisata Bali \\ prabadiah@gmail.com
}

Diterima: 15 Mei 2020. Disetujui: 02 Juli 2020. Dipublikasikan: 30 Desember 2020

\begin{abstract}
Abstrak
Desa Canggu, Bali sangat terkenal di kalangan wisatawan digital nomad. Tujuan penelitian ini untuk mengidentifikasi produk wisata ditinjau dari 4A untuk menunjang kebutuhan wisatawan digital nomad dalam berwisata dan bagaimanakah persepsi wisatawan digital nomad terhadap Desa Canggu, Bali. Teknik analisis data yang digunakan dalam penelitian ini adalah analisis deskriptif kualitatif. Identifikasi produk wisata bersarkan 4A yaitu atraksi, amenitas, aksesibilitas, dan pelayanan tambahan. Wisatawan digital nomad menjadikan Desa Canggu sebagai basecamp dikarenakan seluruh komponen penunjang aktifitas wisata digital tersedia. Adanya komunitas seperti digital camp dan akademi nomad membentuk sebuah ekosistem bagi wisatawan nomad. Adapun hal yang hendaknya dapat dibenahi yaitu faktor lalu lintas dan keamanaan. Faktor tersebut menjadi bahan masukan bagi pemerintah daerah untuk meningkatkan pelayanan dalam menarik wisatawan.
\end{abstract}

Kata Kunci: Digital Nomad, Identifikasi produk 4A, Canggu Bali.

\begin{abstract}
The village of Canggu, Bali is very well known among digital nomadic tourists. The purpose of this study is to identify tourism products in terms of 4A to support the needs of digital nomadic tourists in traveling and how are the perceptions of digital nomadic tourists towards Canggu Village, Bali. The data analysis technique used in this research is descriptive qualitative analysis. Identification of tourism products based on 4A, namely attractions, amenities, accessibility, and additional services. Nomad digital tourists make Canggu Village a base camp because all the supporting components for digital tourism activities are available. The existence of communities such as digital camps and nomad academies forms an ecosystem for nomadic tourists. As for things that should be addressed, namely traffic factors, security.
\end{abstract}

Keywords: Digital Nomad, 4A product identification, Canggu Bali

(C) 2020 Direktorat Kajian Strategis 


\section{PENDAHULUAN}

Bali kini menjadi sebagai salah satu tujuan favorit wisatawan digital nomad dari seluruh dunia. Hal ini senada dengan pernyataan "Bali has become one of the hottest digital nomad hubs in the world, as co-working spaces are continuously opening to accommodate new and returning digital nomad" (Kachroo-Levine, 2017; O'dell, 2017; Delaney, 2016 dalam Haking, 2017). Dalam pernyataan tersebut disebutkan Bali telah menjadi salah satu pusat digital nomad yang hangat, sebagai ruang kerja bersama yang terus di buka untuk mengakomodir wisatawan digital nomad baru ataupun yang datang kembali. Bali mempunyai dua destinasi unggulan bagi wisatawan digital nomad yaitu Ubud dan Canggu. Ubud merupakan destinasi pelopor untuk wisatawan digital nomad yang dimulai dari tahun 2014-an akan tetapi seiring perkembangan, kini Canggu menjadi destinasi digital nomad terpopuler dikalangan wisatawan digital nomad versi Nomadlist.

Desa Canggu, Bali sebagai destinasi nomor satu bagi wisatawan digital nomad meraih nilai 5/5 dari 208 ulasan, yaitu nilai sempurna. Saat ini terdapat 4019 wisatawan digital nomad yang menjadi anggota Nomadlist, 2019 yang berangsur-angsur bertambah setiap harinya. Menyusul peringkat kedua yaitu Seoul dengan nilai 4.7/5 dari 223 ulasan dan peringkat ketiga yaitu Bangkok dengan nilai 4.6/5 dari 230 ulasan. Nomadlist.com juga memasukan Ubud di urutan 33 dengan nilai 4.0/5 dengan 197 ulasan, Seminyak Bali pada urutan 53 dengan nilai 3.89/5 dari 177 ulasan. Rangking ini dapat berubah sewaktuwaktu sesuai dari ranking yang diberikan wisatawan digital nomad. Indonesia cukup tepat jika menempati urutan pertama karena pada umumnya mempunyai atraksi wisata yang sangat beragam yang dapat memuaskan wisatawan digital nomad ini.

Digital nomad merupakan cara berwisata yang merupakan gabungan dari konsep traveling dan living "play and plug". Plug berarti mereka dapat membangun ruang/ domain baru ketika mereka pergi ke tempat baru lain dan berbaur menjadi warga lokal dengan cepat, perangkat gadget yang terintegrasi dengan internet membuat transisi cepat ini terjadi. Bergerak, berarti mereka dapat bergerak sejauh dan secepat yang mereka inginkan. Ini berarti mereka dapat melakukan perjalanan dari satu tempat ke tempat lain, dari satu negara ke negara lain semudah mereka melewati pintu di rumah. Unplug berarti mereka dapat memperbarui atau menghapus data kapan saja ketika tidak lagi diinginkan dan play, berarti melakukan penyamaran di tempat/ daerah baru yaitu mereka dapat hidup sebagai warga lokal setempat.

Tumbuhnya wisatawan digital nomad juga di legitimasi oleh buku The 4-Hour Work Week: Escape the 9-5, Live Anywhere and Join the New Rich, Tim Ferriss, menyatakan bahwa gaya hidup ini menggambarkan generasi wirausaha (entrepreneur) "orang kaya baru". Generasi ini adalah pemilik bisnis dan pekerja lepas (freelancer) yang memanfaatkan kebebasan lokasi untuk lebih sering berwisata dan eksplorasi. Konsep pekerjaan 8 jam di kantor menjadi sesuatu yang lalu dan mulai sudah mulai ditinggalkan. Saat ini bekerja lebih tidak lagi berarti lebih banyak produktivitas. Perusahaan mencari 'pekerja yang mempunyai pengetahuan' dan bersedia memberikan tanggung jawab dan kebebasan kepada pekerja mereka dalam pertukaran produktivitas. Mencintai dan beradaptasi dengan sempurna terhadap perubahan ini, ia adalah kaum millenials.

Mayoritas kaum millenial memiliki konsep baru tentang kekayaan. 
Generasi ini lebih menyukai kebebasan daripada uang atau yang bersifat material. Konsep ini dipraktekkan dengan mengumpulkan pengalaman daripada berharga daripada mempunyai barang fisik. Mereka juga gemar mengumpulkan cap stampel pada paspor daripada membeli mobil baru atau apartemen. Generasi ini dapat disebut sebagai non-konformis dan pemimpi. Persepsi yang berkembang diantara mereka yakni tidak memulai sebuah keluarga pada usia 20-an, akan tetapi sebaliknya, mereka ingin menjelajahi dunia, mengalami budaya baru, bertemu orang yang berbeda, makan makanan baru.

Wisatawan digital nomad ini tidak hanya datang untuk berwisata akan tetapi juga bekerja atau sering disebut "workation". Berkelana dari destinasi ke satu destinasi sambil menyelesaikan pekerjaannya. Membuat jadwal kerja dan rapat sendiri dengan pemandangan gunung atau pasir pantai. Melakukan panggilan virtual dengan atasan atau pertemuan online dengan tim kerja di kedai kopi. Dulu, pekerjaan semacam ini menjadi hal yang mustahil, akan tetapi kini sangat mungkin di wujudkan. Disatu sisi, pemerintah juga ingin menarik kelompok turis digital nomad datang lebih banyak ke Indonesia, hal ini disampaikan pada Rakornas 2019 ini yang diselenggarakan oleh Kementerian Pariwisata dengan tema utama yang dibahas yaitu digital destinations dan digital nomads. Tentunya jika pemerintah ingin menarik wisatawan digital nomad untuk berwisata ke Indonesia khususnya ke Bali harus dapat menyiapkan kebutuhannya sebagai destinasi digital. Dari kunjungan tersebut akan membuat persepsi di benak wisatawan digital nomad.

Dari hal diatas, maka penulis tertarik untuk menggali lebih dalam produk wisata ditinjau dari 4A Cooper,
Fletcher, dan Gilbert (2005) dalam buku mereka yang berjudul Tourism, Principle and Practice, menjabarkan 4 komponen utama sebuah destinasi wisata. Keempat komponen utama tersebut adalah (Atraksi, Amenitas, Aksesibiliti dan Ancilari) untuk menunjang kebutuhan wisatawan digital nomad di Desa Canggu, Bali? Bagaimanakah persepsi wisatawan digital nomad terhadap Desa Canggu, Bali?

Adapun komponen dari 4A dalam suatu destinasi menurut Cooper, Fletcher, dan Gilbert (2005) meliputi: Pertama, Attractions atau daya tarik merupakan komponen dari sebuah destinasi wisata yang dapat menimbulkan ketertarikan wisatawan untuk mengunjungi destinasi tersebut. Hal-hal yang dapat menimbulkan ketertarikan wisatawan untuk berkunjung adalah seperti panorama alam, keanekaragaman budaya, atau hal-hal yang merupakan buatan manusia, seperti, even, atau taman/ tempat rekreasi. Kedua, Accessibilities yaitu ketersediaan sarana dan prasarana transportasi untuk menuju dan meninggalkan sebuah destinasi wisata, seperti ketersediaan jalan, moda transportasi, terminal, pelabuhan, bandara, dan lainnya. Ketiga, Amenities yaitu ketersediaan fasilitas penunjang bagi pengunjung/ wisatawan, seperti penginapan/ akomodasi, penyediaan makanan dan minuman/ konsumsi, cenderamata/ souvenir, agen perjalanan, serta pemandu dan pusat informasi wisata. Keempat, Ancillary Services yaitu, ketersediaan fasilitas pendukung kegiatan wisatawan selama berada di sebuah destinasi wisata, seperti, layanan perbankan, layanan kesehatan, layanan keamanan, toilet umum, jaringan komunikasi, kurir/pos, dan lain sebagainya.

Dikutip dari kamus Oxford, The definition of the word 'digital' is described as "Involving or relating to the 
use of computer technology" and 'nomad' as "A member of a people that travels from place to place to find fresh pasture for its animals and has no permanent home" ("Nomad", 2016). Dari kutipan diatas, kata "digital" dapat mendeskripsikan "melibatkan atau berhubungan dengan penggunaan teknologi komputer" dan 'nomad' sebagai seorang anggota dari orang yang bepergian dari satu tempat ke tempat lain untuk menemukan tempat yang segar dan tidak mempunyai tempat tinggal yang tetap.

Konsep digital nomad kemudian berkembang menjadi seorang pengembara digital yang mempunyai pekerjaan yang dapat dikerjakan jarak jauh di bidang teknologi seperti desain web, pemrograman, atau pemasaran online. Mereka memanfaatkan keuntungan dari pekerjaan mereka untuk berkeliling dunia. Fleksibilitas kerja jarak jauh dapat dikerjakan dari rumah, mengurangi biaya transportasi dan menghindari gangguan-gangguan kantor. Digital nomad memilih lokasi mereka berdasarkan pertimbangan waktu luang, bukan pekerjaan (Muller 2016).

Terdapat perbedaan jenis wisatawan dalam penentuan karakteristik yang membentuk identitas digital nomads. Dalam karyanya, Kayleigh Franks (2016) menyatakan bahwa digital nomad hanyalah subset tertentu dari jenis nomad lainnya, seperti: Global digital nomad, konsep ini dikembangkan oleh Caren Kaplan, yang mendefinisikan individu nomaden global yang dapat bergerak melalui ruang yang tampaknya tidak masuk akal tanpa mempunyai pegangan (Kaplan, 1996). Berlawanan dengan nomaden digital, nomaden global tidak perlu menggunakan teknologi sebagai sarana utama kelangsungan hidup mereka saat bepergian. Banyak di antara mereka yang bekerja sebagai pekerja tetap sampai mereka mengumpulkan dana yang diperlukan untuk bepergian, atau bekerja secara sporadis untuk mendapatkan cukup uang untuk melanjutkan hidup.

Backpackers sering dikaitkan dengan individu yang lebih muda, istilah backpacking mengacu pada turis hemat yang bepergian secara mandiri untuk waktu yang relatif lama (satu hingga beberapa bulan), tanpa tujuan tertentu. Setelah perjalanan mereka, para pelancong kembali ke negara asalnya (Kannisto et al., 2014). Bentuk nomadisme, backpacking pada kenyataannya lebih dekat dengan grand tour praktik bangsawan Eropa selama abad 17 dan 18 bagian dari pendidikan bangsawan muda (Urry, 2000). Adapula para ekspatriat yang melakukan perjalanan untuk bekerja, para migran yang menetap di tempat-tempat asing untuk mencari kondisi kehidupan yang lebih baik, para pengungsi yang melarikan diri mencari suaka politik, etnis minoritas, seperti populasioma mengikuti tradisi kehidupan pastoral yang telah berusia seabad, dan tentu saja, para wisatawan yang berlibur untuk bersantai.

Mengacu dengan draft Kemenpar, adapun tiga segmen utama wisatawan digital nomadic yaitu pertama Glampacker "Millenial Nomad", merupakan wisatawan digital nomad yang mengembara untuk melihat dunia yang instagramable, sebutan untuk tempat yang ikonik untuk berfoto atau destinasi wisata yang viral di media sosial. Wisatawan ini menginginkan fasilitas akomodasi dan pelayanan yang nyaman dan memuaskan. Mereka ini berpenghasilan menengah sampai atas. Kedua, Luxapacker "Luxurious Nomad", merupakan turis pengembara dengan fasilitas mewah. Mereka menginginkan fasilitas super de-luxe dan sangat mementingkan kenyamanan dan kemewahan saat berpetualang. Ketiga, 
Flashpacker "Digital Nomad" yaitu turis yang menetap sementara di satu tempat, sembari bekerja dari mana saja. Mereka ingin menjalani hidup seperti masyarakat lokal. Dalam penelitian ini, penulis lebih berfokus dengan wisatawan digital nomad sesuai dengan keadaan di lapangan.

Adapun beberapa motivasi yang melatarbelakangi gaya hidup seorang digital nomad menurut Reichenberger, 2017 adalah sebagai berikut: Pertama, kebebasan profesional yaitu motivasi untuk bekerja secara mandiri, memilih dan menyusun pekerjaan itu terkait dengan hasrat seseorang dan meningkatkan perasaan dari tujuan. Kedua, kebebasan spasial yaitu motivasi untuk melakukan pekerjaan virtual sambil belajar tentang yang lain gaya hidup, budaya, norma dan opini. Ketiga, kebebasan pribadi yaitu motivasi untuk menjadi lebih produktif, kreatif, dan paling penting, pengembangan diri dan peningkatan kebahagiaan.

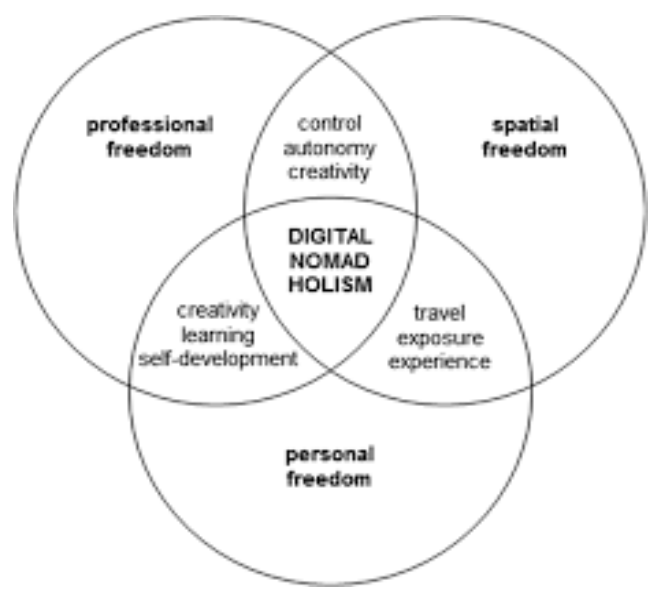

Gambar 1. Digital Nomad Holism

Pada gambar 1 digital nomad holism dapat dilihat korelasi dari tiga aspek perbedaan dari kebebasan. Terdapat beberapa irisan pada setiap kebebasan yaitu antara kebebasan professional dan kebebasan personal terdapat gabungan kreatifitas, belajar dan pengembangan diri. Pada irisan kebebasan spasial dan kebebasan personal, terdapat gabungan antara perjalanan, paparan dan pengalaman. Pada irisan kebebasan professional dan kebebasan spasial terdapat control, otonomi dan kreativitas.

\section{METODE}

\subsection{Lokasi Penelitian}

Penelitian ini berlokasi di Desa

Canggu, Kecamatan Kuta Utara,

Kabupaten Badung, Bali.

\subsection{Jenis dan Sumber Data}

\subsubsection{Jenis Data}

Penelitian ini menggunakan jenis penelitian exploratif (Exploratory Research) dengan pendekatan kualitatif. Metode penelitian ini berusaha mendeskripsikan objek penelitian berdasarkan data dan fakta yang sebenarnya.

\subsubsection{Sumber Data}

Penelitian ini menggunakan data primer data sekunder. Data primer yang diperoleh langsung dari sumber aslinya yaitu dusun yang menjadi objek penelitian. Dalam hal ini yang dimaksud data yang diperoleh peneliti adalah hasil observasi partisipan di Desa Canggu, untuk mengindentifikasi potensi wisata yang ada di desa tersebut. Data sekunder penulis dapatkan dari artikel-artikel di internet, jurnal atau situs yang terkait dengan penelitian yang dilakukan.

\subsection{Teknik Pengumpulan Data}

Pengumpulan data yang dilakukan dalam penelitian ini yaitu:

\subsubsection{Observasi}

Teknik pengumpulan data dilaksanakan dengan observasi partisipan 
Jennings (2001). Dalam melakukan observasi, peneliti ikut terlibat dalam kegiatan yang diamati sehingga mendapatkan data yang sebenarnya, merasakan kegiatan bekerja di coworking dan café serta berwisata di Desa Canggu.

\subsubsection{Wawancara}

Pengumpulan data dengan cara wawancara mendalam ini dilakukan untuk mendapatkan data tambahan yang tidak diperoleh pada saat observasi di lokasi penelitian. Teknik sampling menggunakan gabungan dari purposive sampling dan snowball sampling. Purposive sampling (Sugiyono, 2015) pengambilan sumber data dengan pertimbangan tertentu, seperti orang yang dianggap tahu tentang apa yang diharapkan. Snoball sampling untuk memberbanyak jumlah subjek apabila diperlukan informasi yang lebih mendalam. Wawancara ini dilakukan dengan cara memberikan pertanyaan kepada informan 15 wisatawan digital nomad yang sudah tinggal di Desa Canggu selama kurang lebih 1 bulan.

Hal ini dilakukan agar mendapatkan pandangan yang dalam terhadap persepsi informan tersebut. Durasi wawancara dilakukan selama 1 jam.

\subsubsection{Studi Pustaka}

Studi pustaka adalah teknik pengumpulan data dengan mengadakan studi penelaah terhadap buku-buku, literatur-literatur, catatan-catatan, dan laporan-laporan yang ada hubungannya dengan masalah yang dipecahkan.

\subsubsection{Dokumentasi}

Metode dokumentasi dalam penelitian ini dimaksudkan untuk memperoleh data dengan dokumentasi, yaitu dengan cara mengambil gambar di Desa Canggu, Kabupaten Badung, Bali.

\subsection{Teknik Analisis Data}

Dalam penelitian ini dilakukan analisis data kualitatif. Menurut Creswell (2010), penelitian kualitatif merupakan suatu proses penyelidikan untuk memahami masalah sosial atau masalah manusia, berdasarkan pada penciptaan gambar holistik yang dibentuk kata-kata, melaporkan pandangan informan secara terperinci, dan disusun dalam sebuah latar ilmiah. Analisis data dilakukan menggunakan versi Miles dan Huberman, dalam Sugiyono (2013) bahwa aktivitas dalam analisis data kualitatif dilakukan secara interaktif dan berlangsung secara terus-menerus sampai tuntas sehingga datanya jenuh. Aktivitas meliputi reduksi data (data reduction), penyajian data (data display) dan penarikan kesimpulan (verification).

Dalam penelitian ini, peneliti menggunakan dua macam triangulasi yaitu triagulasi teknik dan triagulasi sumber. Dalam aplikasi triangulasi teknik, penulis menggunakan teknik pengumpulan data yang berbeda-beda untuk mendapatkan data dari sumber data yang sama. Penulis menggunakan observasi partisipatif, wawancara semi mendalam dan dokumentasi untuk sumber data. Triangulasi sumber untuk mendapatkan data dari sumber yang berbeda-beda dengan teknik yang sama.

\section{HASIL DAN PEMBAHASAN}

\subsection{Perkembangan Wisatawan Digital Nomad di Desa Canggu}

Wisatawan digital nomad memberi Desa Canggu dengan julukan "a hipster paradise of digital nomade community". Hipster diartikan sebagai orang yang menyukai atau tertarik pada hal-hal baru yang tidak biasa atau dapat disebut anti- 
mainstream. Pada era 1940-an, istilah hipster digunakan untuk menggambarkan penggemar jazz yang tertarik pada mode, orang-orang yang gemar bergaul dan bersikap santai. Berbeda dengan 'hippies', hipster lebih dinamis dalam berevolusi. Penulis Matt Granfield, hipster berkembang pada tahun 2010-an, adalah mereka yang menggunakan sepeda fixed gear, gemar merajut dan menjadi vegan. Hal ini juga tercermin pada perilaku wisatawan digital nomad yang tinggal di Canggu. Hal ini nampak dari gaya pakaiannya yang gemar menggunakan baju yang santai tetapi terkesan trendi, gemar menggendarai japp style 'sepeda motor custom' dengan kesan klasik, mereka juga gemar mengkonsumsi makanan sehat.

Sebelum Desa Canggu terkenal sebagai basecamp para digital nomad seperti sekarang ini, Ubud merupakan tempat yang lebih dulu terkenal dengan wisatawan digital nomad. Ubud terkenal dengan coworking space pertama di Bali bernama Hubud yang dipelopori oleh Steve Munroe, Peter Wall, dan John Alderson. Kehidupan di Ubud lebih kepada kaum 'hippies'. Pada tahun 2016an, kemudian kehidupan digital nomad beralih ke Desa Canggu, hal ini tidak terlepas dari para digital nomad yang membuat start up seperti Tina dan Emilio dari Australia membangun sekolah coding bernama Institute of Code di salah satu daerah populer di Bali yaitu Desa Canggu. Salah satu kesuksesan bisnis ini adalah ditawarkannya kelas yoga dan meditasi secara reguler. Selain itu, Pieter Levels - terkenal dengan misi "12 startup dalam 12 bulan", meluncurkan Nomadlist.com, sebuah website berisi data lebih dari 500 kota yang memperlihatkan berbagai kota terbaik untuk digital nomad.
Kehadiran wisatawan digital nomad di Canggu juga di dukung oleh Nomad Academy. Harry Verma adalah pendiri The Nomad Academy, program akselerator untuk para profesional muda yang berani dengan tantangan untuk sukses dan mengejar karir. Program ini dilakukan 3 bulan menyatukan individu untuk bepergian ke tujuan yang menginspirasi di seluruh dunia, sambil menyelesaikan kursus dan lokakarya online premium untuk mempelajari keterampilan sesuai permintaan dan pola pikir wirausaha untuk menemukan karier yang luar biasa. Munculnya kursus online kelas dunia berarti semua orang dapat mempelajari keterampilan untuk karier yang luar biasa dari mana saja. Adapun tiga Negara menjadi tujuan digital nomad ini adalah Amerika Latin (Colombia, Peru dan Chile), Afrika (Nambia, Afrika Selatan, Mauritius), Asia Tenggara (Kuala Lumpur, Malaysia, Chiang Mai, Thailand dan Canggu, Bali). Mereka mempraktekkan sebuah "slow travel" (One Month in Each Country, Long Enough to Change Mindset).

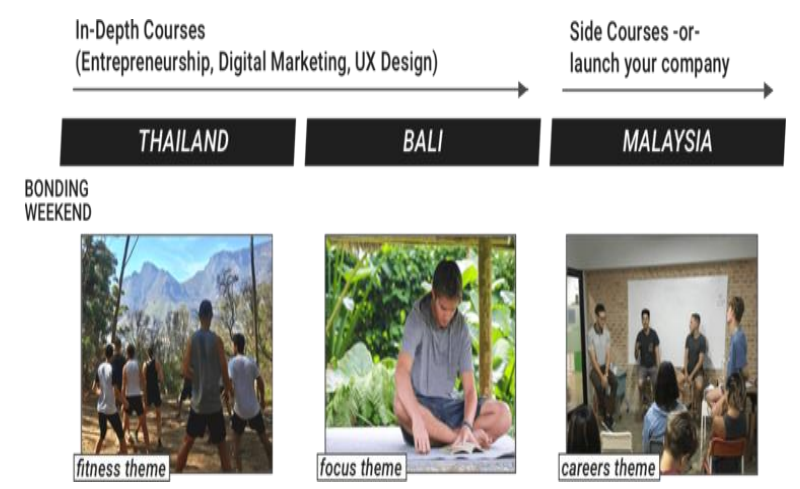

Gambar 2. Kegiatan Nomad Academy

Sumber: Nomad Academy.com

Kegiatan Nomad Academy dilakukan selama tiga bulan. Untuk Asia Tenggara, mereka mengambil lokasi Thailand, Bali dan Malaysia. Mereka tinggal selama 1 bulan penuh dengan bebagai kegiatan workshop dan kursus. 
Para peserta tergabung dari bebagai negara dan berbagai latar belakang. Selama berada di Bali, mereka melalukan focus theme untuk membangun usahausaha mereka, melakukan workshop terkait kewirausahaan, menggali kemampuan seperti soft-skill. Mereka juga rutin untuk berwisata keliling Bali dengan para teman-teman dalam grup.

\section{Analisis Produk Wisatawan Digital Nomad di Desa Canggu}

Kabupaten Badung merupakan pintu gerbang wisatawan datang ke Bali. Dengan branding dan tagline Badung: The Soul of Bali dengan makna Badung merupakan nyawanya dari pariwisata Bali sehingga sangat memungkinkan jika dapat dikembangkan untuk menampung kebutuhan para wisatawan. Kabupaten Badung belum melirik tajam pada wisatawan digital nomad akan tetapi Desa Canggu menjadi tempat yang sangat berpotensi menjadi basecamp dari wisatawan ini. Adapun produk bagi wisatawan digital nomad di Canggu sebagai berikut:

\section{Identifikasi atraksi bagi wisawatan digital nomad}

Wisatawan digital nomad datang ke Canggu, tidak hanya untuk bekerja melainkan berwisata. Mereka selalu menyempatkan waktu untuk berwisata dan menikmati keadaan sekitar, hanya saja mereka tidak seperti wisatawan lainnya yang terikat pada jadwal. Wisatawan digital nomad mempraktekan slow travel karena mereka akan mendiami suatu tempat cenderung lama seperti 1 bulan. Hal ini membuat mereka dapat menjelajah ke semua destinasi wisata. Di Canggu terdapat berbagai pilihan atraksi wisata alam dan atrakasi buatan yang dapat menunjang aktifitas wisatawan digital nomad berupa daya tarik wisata alam maupun buatan.

Daya tarik wisata alam di Desa Canggu didominasi oleh daya tarik wisata pantai karena Desa Canggu ini berlokasi dekat dengan pantai. Tidak hanya itu, Canggu juga dijuluki "Ubudnya Kuta" karena masih terdapat hamparan sawah. Terdapat 9 pantai di Desa Canggu yang menjadi daya tarik yaitu Pantai Canggu, Pantai Echo Beach (Batu Mejan), Pantai Berawa, Pantai Batu Bolong, Pantai Kayu Putih, Pantai Pererenan, Pantai Seseh, Pantai Nelayan dan Pantai Mengening. Daya tarik wisata yang ditawarkan di 9 pantai tersebut sebagian besar sama untuk dijadikan pilihan utama wisata sebagai tempat berenang, melihat sunset, berselancar, memancing dan bersantai.

Selain daya tarik wisata alam berupa pantai, Desa Canggu pun memiliki daya tarik wisata buatan. Desa Seni Yoga merupakan sebuah tempat yang didirikan untuk tujuan memberikan pelayanan kesehatan dan kebugaran tubuh pengunjungnya. Lokasi tempat dan bangunannya sendiri di desain sedemikian rupa sehingga tampak sangat menyatu dengan alam sekitar Canggu yang khas pedesaan, contohnya lokasi paviliun untuk kelas yoga, dimana lokasinya berada di tengah areal kebun organik dengan sisi terbuka. Finns Recreation yang mempunyai fasilitas pusat kebugaran seperti tennis dan bowling serta taman air. Tidak hanya destinasi wisata yang di cari oleh wisatawan digital nomad, adapun faktor pendorong wisatawan digital nomad memilih Canggu yaitu faktor cuaca, koneksi internet, co-working spaces, tempat hiburan malam, toleransi,

Faktor yang mendorong wisatawan digital nomad memilih Desa Canggu yaitu pertama, faktor cuaca. Wisatawan digital nomad ini memberi julukan Canggu sebagai 'Tropical 
Paradise', sangat tepat karena sebagai pulau tropis, Canggu mempunyai suhu rata-rata 33 derajat celcius. Hal ini sangat tepat bagi wisatawan yang ingin melarikan diri dari suasana musim dingin di negaranya. Mereka dapat mengemasi barang-barangnya dengan ringkas light travel' sehingga tidak dipersuit dengan membawa pakaian yang banyak dan sangat mempermudah gerak mereka jika ingin berpindah-pindah tempat.

Kedua, koneksi internet merupakan prioritas bagi wisatawan digital nomad. Wisatawan digital nomad tidak dapat hidup tanpa koneksi internet yang stabil, mereka akan merasa sangat gelisah jika tidak terkoneksi pada saat membutuhkannya. Rata-rata di Canggu mempunyai kecepatan internet $20 \mathrm{mbps}$ yang mana cukup kencang untuk menunjang kebutuhan pekerjaan dari wisatawan digital nomad. Setiap cafe, restoran hingga warung rata-rata sudah mempunyai akses wifi gratis sehingga sangat memudahkan jika mereka ingin terkoneksi dengan internet dimana saja.

Ketiga, adanya coworking space, sebutan tempat bekerja para wisatawan digital nomad. Menjadi wisatawan digital nomad sangat memungkinkan untuk bertemu dengan teman seprofesi bahkan dapat menemukan rekan baru untuk menunjang pekerjaan. Coworking spaces are an interesting dimension of the digital nomad sociability and lifestyle spectrum. Usually, they involve independent computer-based work in open, shared offices, which freelancers, digital nomads or entrepreneurs can rent out by the day or monthly. Coworking spaces usually feature office facilities and offer fast Wi-Fi in a relaxed, modern environment (O'Brien, 2011). Coworking lebih kepada bagaimana digital nomad bertemu dengan sesama komunitas daripada tempat untuk bekerja.
Co-working space biasanya diisi dengan banyak meja dan ruang pertemuan pribadi serta area tempat duduk di luar, untuk mengakomodasi mereka yang suka bekerja di suasana terbuka. Biasanya, ruang kerja bersama memiliki dapur bersama, isi ulang kopi tanpa batas, dan acara menyenangkan setiap minggu untuk membantu para digital nomad untuk bertemu teman kerja sama lainnya, menjelajahi daerah setempat dan kadang-kadang mereka menyelenggarakan acara minat khusus dengan pembicara dan tamu yang memotivasi. Di Canggu mulai berkembang co-working dimulai dari Dojo Bali, Outpost Coworking \& Coliving, Matra Coworking \& Coliving dan Tropical Nomad.

Tidak hanya co-working space, wisatawan digital nomad juga gemar untuk bekerja di café dan restoran. Mereka bekerja sambil menyeruput secangkir kopi untuk mencari inspirasi. Rata-rata waktu yang dihabiskan untuk bekerja di café ini selama 1-3 jam. Mengutip pernyataan Nick Wharton, travel blogger Goats on the road yang menyatakan,

"Every single cafe in this town has electrical sockets on every wall and they basically expect that you're going to bust out your computer and plug away for a few hours after your meal. Aside from the regular cafes that are well set up for digital productivity, there are also numerous co-working spaces available as well".

Dari pernyataan diatas, para pengusaha sudah siap dalam mengantisipasi kebutuhan wisatawan digital nomad dengan melengkapi café dengan beberapa fasilitas dasar seperti stopkontak yang memudahkan wisatawan digital nomad untuk mengisi ulang baterai telepon genggam ataupun laptopnya. 
Keempat, keberadaan pilihan restoran organik dan vegan. Faktor yang mendukung kegiatan wisatawan digital nomad salah satunya adalah restoran dan café. Banyaknya pilihan restoran dan café di Desa Canggu sangat berpengaruh dengan kunjungan wisatawan digital nomad karena beberapa dari mereka memilih untuk bekerja di fancy café seperti yang instagramable. Bekerja di restoran atau café, hal yang menjadi pertimbangannya adalah tersedianya ruangan yang mempunyai pendingin ruangan, ruangan terbuka dengan taman, pemandangan sawah, sofa yang nyaman, makanan yang menarik sehingga hal ini dapat mendorong inspirasi sekaligus menjadi content untuk website mereka.

Kelima, kesehatan juga menjadi perhatian bagi wisatawan digital nomad seperti air, nyamuk dan Bali belly (sebuah ungkapan bagi wisatawan yang mengalami perasaan tidak enak di perut akibat menyantap makanan Bali). Wisatawan digital nomad merasa sedikit ketakutan jika mengonsumsi air langsung dari keran untuk menggosok gigi karena faktor higinitas sanitasi. Hal ini memang berbeda dari negara mereka, dimana air dapat dikonsumsi secara langsung dari keran. Sebagai negara tropis, nyamuk menjadi sesuatu yang sering dihadapi oleh tamu. Mereka mempunyai ketahanan tubuh yang berbeda dengan penduduk lokal sehingga mereka sering merasa sangat tidak nyaman oleh nyamuk. Mereka takut terserang oleh penyakit demam berdarah. Fasilitas lainnya juga yaitu apotik sudah tersedia sdengan baik. Dokter dapat dipanggil on call dengan gojek medicine.

Keenam, wisatawan digital nomad juga sangat memperhatikan kehidupan malam, di Desa Canggu kini terdapat beberapa tempat hiburan tempat mereka menikmati kehidupan jika penat bekerja. Finns Beach Club, Black Cat, La Brisa, Old Man's, The Lawn, Pretty Poison,
Gimme Shelter, dan lain-lain. Kehidupan malam di Desa Canggu menjadikan tempat ini sebuah destinasi yang lengkap bagi wisatawan digital nomad. Tidak saja itu, karena Desa Canggu terletak di posisi yang strategis, wisatawan digital nomad dapat dengan mudahnya mengkases hiburan malam ke Seminyak dan juga Kuta.

Ketujuh, toleransi menjadi sebuah perhatian bagi wisatawan digital nomad. Hal ini karena mereka datang dari berbagai negara dan mempunyai karakteristik yang beragam yang sangat memungkinkan adanya perbedaan dengan kebiasaan penduduk lokal. Toleransi ini juga tenyata juga berlaku untuk kaum LGBT (lesbian, gay, biseksual, dan transgender). Masyarakat Desa Canggu tidak memandang orientasi seksual seseorang apabila tidak membuat atau berlaku yang di luar dari norma adat setempat. Masyarakat lokal Desa Canggu dinilai ramah terhadap wisatawan asing yang datang berkunjung. Sebagian besar masyarakat sudah fasih menggunakan bahasa inggris dalam kehidupan seharihari. Ramah terhadap perempuan juga menjadi suatu tolak ukur yang dinilai oleh wisatawan digital nomad.

\section{Identifikasi amenitas bagi wisawatan digital nomad}

Seiring dengan pertumbuhan pariwisata dan bermunculannya wisatawan digital nomad ke Desa Canggu, para pengusaha di Canggu tidak ingin melewatkan kehadiran wisatawan ini sehingga mereka berlomba untuk menawarkan akomodasi mulai muncul guna mengakomodir kebutuhan wisatawan ini. Wisatawan digital nomad mempunyai banyak alternatif pilihan tinggal seperti villa, AIRBNB, hotel, hostel, surf camp, guest house, homestay dan yang sedang menjadi tren adalah $c o$ living. 
Wisatawan digital nomad merupakan wisatawan yang mempunyai waktu tinggal dengan jangka waktu menengah sampai dengan jangka panjang. Dari observasi penulis, terdapat 4 jenis tipe akomodasi bagi wisatawan digital nomad yaitu villa, homestay, surf camp dan co-living.

Wisatawan digital nomad menyewa akomodasi berupa villa selama dengan rentang waktu bulanan. Alasan wisatawan digital nomad memilih tipe akomodasi villa yaitu mereka ingin merasa bekerja dengan privat dan agar mudah untuk mengundang temantemannya datang untuk berpesta. Akomodasi berupa villa juga dilengkapi beberapa fasilitas berupa dapur, taman dan kolam renang yang sangat membuat nyaman. Villa merupakan tempat tinggal yang nyaman untuk tinggal, bekerja dan menikmati halaman dengan kolam renang. Mereka sering menyebutnya "staycation" yang terdiri dari stay dan vacation.

Wisatawan digital nomad juga mempunyai pilihan tinggal di usaha skala kecil seperti homestay/guesthouse. Akomodasi yang mendominasi di Desa Canggu adalah homestay/guest house yang dimiliki oleh warga lokal. Adapun alasan wisatawan digital nomad memilih tipe akomodasi homestay. Homestay/ guest house mempunyai fleksibilitas waktu dan harga yang dapat dinegosiasi. Mereka dapat menyewa secara harian, mingguan hingga bulanan. Harga sewa per bulan/ per minggu dan per hari dengan harga yang sangat murah baginya. Harga untuk menyewa per bulan yaitu Rp. 4.000.000/ kamar. Hampir semua homestay/guesthouse dilengkapi fasilitas wifi yang cukup kencang untuk menunjang aktifitas pekerjaan wisatawan digital nomad. Harga yang sangat kompetitif jika melihat dari fasilitas dan fleksibilitas yang ditawarkan. Selain harga yang kompetitif, wisatawan digital nomad juga senang berbaur dengan warga lokal dan mendalami hidup sebagai bagian dari warga lokal.

Wisatawan digital nomad juga memilih Surf camp juga menjadi salah satu pilihan alternative bagi yang gemar menghabiskan waktu luang untuk berselancar. Sesuai dengan Namanya, akomodasi ini mempunyai ceruk pasar "niche" bagi penghobi selancar. Kelebihan akomodasi ini tidak hanya sebatas akomodasi akan tetapi mereka dapat bertemu dengan orang-orang yang mempunyai hobi yang sama dan dapat bertukar pikiran dan menjalin relasi baru. Wisatawan digital nomad juga memunculkan tren akomodasi co-living. Akomodasi ini terlihat sama dengan akomodasi pada umumnya, menawarkan kamar akan tetapi co-living mempunyai keunggulan berupa fasilitas tempat kerja yang dapat di gunakan bersama maupun tempat kerja yang dapat disewa secara privat. Jenis akomodasi ini juga dapat mempertemukan teman yang mempunyai kesamaan dalam profesi yaitu digital nomad dan membentuk komunitas.

Digital nomad identik dengan memilih destinasi tempat ia akan hidup di destinasi yang mempunyai biaya yang lebih rendah daripada penghasilannya. Beberapa pengeluaran yang menjadi pertimbangan wisatawan digital nomad dalam memilih destinasi sebagai tempat hidup adalah biaya hidup untuk satu orang untuk perbulannya. Dilansir dari Nomadlist, untuk tinggal di hotel memerlukan USD 458/bulan atau setara dengan sewa hotel USD 21/ malam, Air BNB USD 1.251/ bulan atau setara dengan USD 41/malam, Coworking USD 247/bulan, makan malam USD 3.54/ sekali makan, kopi USD 1.77, beer USD 1.77 untuk ukuran $0.5 \mathrm{~L}$, coca cola USD 0.59/ kaleng. Dari hal ini dapat disimpulkan bahwa Desa Canggu mempunyai pilihan akomodasi yang 
beragam untuk menunjang kebutuhan wisatawan digital nomad.

\section{Identifikasi aksesibilitas bagi wisawatan digital nomad}

Kunjungan wisatawan digital nomad datang ke Indonesia juga tidak terlepas dari kebijakan visa pemeintah Indonesia. Menurut Peraturan Presiden RI Nomor 21 Tahun 2016 Tentang Bebas Visa Kunjungan, pemerintah memberikan bebas visa kepada 169 negara. Indonesia mempunyai 3 jenis visa kunjungan yaitu visa kunjungan saat kedatangan, visa kunjungan satu kali perjalanan dan visa kunjungan beberapa kali perjalanan. Kebijkan bebas visa bagi wisatawan selama 30 hari. Wisatawan digital nomad ini juga dapat mengajukan visa extension ketika sampai di Bali dengan perpanjangan lama tinggal 30 hari. Wisatawan juga dapat mengajukan visa sosial budaya. Dengan visa ini, orang asing dapat berkunjungan sekali ke wilayah Indonesia hanya untuk tujuan kunjungan keluarga, wisata dan lainnya diluar kebutuhan bisnis atau kerja. Visa kunjungan sosial budaya diberikan lama tinggal 60 (enam puluh) hari, dapat diperpanjang sebanyak 4 (empat) kali dan setiap kali perpanjangan diberikan lama tinggal 30 (tiga puluh) hari.

Wisatawan digital nomad juga mempertimbangkan akses ke destinasi wisata. Untuk menuju Desa Canggu dapat dapat ditempuh sejauh $18 \mathrm{~km}$ melalui jalur darat dari Kota Denpasar, kurang lebih selama 45 menit dari Bandara Udara Internasional Ngurah Rai. Jalan untuk menuju Desa Canggu sudah didukung dengan jalan raya aspal untuk memudahkan mengakses pusat kawasan wisata yang ada di Desa Canggu menggunakan kendaraan roda dua, mobil, hingga bus. Akses menuju Desa Canggu dapat dilewati dari arah jalan raya Kuta, jalan raya Legian, jalan raya
Seminyak ataupun jalan raya Kerobokoan. Mobilitas wisatawan digital nomad di Desa Canggu didominasi dengan menggunakan sepeda motor. Hal ini akan dapat memudahkan mereka untuk bergerak dari satu tempat ke tempat lainnya. Fasilitas untuk pejalan kaki memang masih sangat minim, tidak adanya fasilitas trotoar untuk pelajan kaki menjadikan wisatawan susah untuk menyusuri jalan. Jalanan yang begitu sempit dan padatnya lalu lintas di Desa Canggu juga tidak memungkinkan bagi pengendara sepeda ataupun pejalan kaki.

\section{Identifikasi ancilari bagi wisawatan digital nomad}

Pelayanan tambahan merupakan salah salah satu elemen dari 4A yang berperan penting bagi suatu destinasi wisata yang hendaknya dapat disiapkan oleh pemerintah daerah baik untuk wisatawan maupun untuk pelaku pariwisata. Pelayanan yang disediakan termasuk pemasaran, pembangunan fisik (jalan raya, air minum, listrik, telepon, dan lain-lain) serta mengkoordinir segala macam aktivitas dan dengan segala peraturan perundang-undangan baik di jalan raya maupun di destinasi wisata. Ancilliary juga merupakan hal-hal yang mendukung sebuah kepariwisataan, seperti lembaga pengelolaan, Tourist Information Centre, agen perjalanan dan stakeholder yang berperan dalam kepariwisataan seperti asosiasi.

Pelayanan tambahan sudah mulai dikembangkan seperti adanya jasa travel agent, penukaran mata uang asing, visa extension, listrik, telepon, ATM. Dari beberapa fasilitas yang sudah dikembangkan namun di Desa Canggu sangat kekurangan akses pagi pejalan kaki yang memadai seperti trotoar dan tempat penyebrangan yang aman bagi wisatawan. 


\section{Analisis Pasar Wisatawan Digital Nomad di Desa Canggu}

Dari 15 informan wisatawan digital nomad yang tinggal di Desa Canggu selama kurang lebih 1 bulan, mereka memilih untuk tinggal di Desa Canggu dikarenakan mempunyai suasana yang santai dan dekat dengan pantai. Wisatawan digital nomad yang berkunjung ke Desa Canggu mempunyai karakteristik sebagai berikut: Pertama, Pola Perjalanan. Perjalanan wisatawan digital nomad akan sangat berbeda dengan wisatawan pada umumnya. Mereka akan memilih tempat untuk tinggal dengan beberapa pertimbangan yaitu infrastruktur, internet dan biaya hidup. Wisatawan tipe ini akan tinggal lebih lama di suatu destinasi dibandingkan wisatawan lainnya yang berpindah-pindah dengan susunan acara perjalanan. Mayoritas akan tinggal selama 30 hari dan kemudian pergi ke negara terdekat di Asia seperti Singapura, Malayasia atau Thailand untuk beberapa minggu dan kemudian akan kembali ke Bali.

Kedua, Pekerjaan. Wisatawan digital nomad merupakan pekerja lepas yang tidak terikat oleh ruang dan waktu akan tetapi selalu terhubung dengan internet. Pekerjaan mereka dapat dilakukan sembari dengan kegiatan berwisata. Rata-rata dari mereka mempunyai pekerjaan sebagai business coach, guru yoga sekaligus content creator, website developer, freelancer, web designer dan bloger. Semua pekerjaan ini berbasis internet dan mempunyai dan tidak menuntut hadir di kantor akan tetapi dinilai berdasarkan efektivitas dan deadline suatu pekerjaan.

Ketiga, Rutinitas. Kehidupan rutin wisatawan digital nomad akan sangat berbeda dengan wisatawan pada umumnya. Jika wisatawan pada umumnya sudah membawa rancangan perjalanan dan tempat yang akan di kunjungi, wisatawan nomad menerapkan konsep "slow travel" karena tinggal lebih lama sehingga tidak terburu-buru. Wisatawan digital nomad mengatur waktu bekerja dan berwisata sesuai dengan tuntutan dari pekerjaannya. Mereka dapat menghabiskan waktu pada pagi hari di pantai dan mulai efektif bekerja pada tengah malam karena menyesuaikan jam dengan negara asal. Wisatawan digital nomad akan lebih cenderung memilih untuk makan seharihari di warung lokal dikarenakan harga yang lebih murah dan memilih bekerja di café atau co-working space jika membutuhkan tempat untuk bekerja.

\subsection{Persepsi Wisatawan digital nomad tentang Canggu}

Terdapat 15 orang wisatawan digital nomad di Canggu yang menjadi informan pada penelitian ini. Informan merupakan wisatawan digital nomad yang sudah tinggal di Desa Canggu kurang lebih selama 1 bulan. berikut profil wisatawan digital nomad pada tabel 1.

Dari tabel 1, profil wisatawan digital nomad rata-rata berasal dari benua Eropa, Amerika dan Australia. Rentang usia wisatawan digital nomad ini mulai dari 22 tahun hingga 43 tahun dimana pada umur tersebut masih sangat memungkinkan seseorang produktif dan mudah untuk berpindah-pindah. Pekerjaan wisatawan digital nomad juga mayoritas bekerja pada sektor teknologi yang mengandalkan kecepatan internet dan tidak memerlukan hadir secara fisik di kantor karena pekerjaan mereka dapat dilakukan dimana saja. 
Tabel 1. Profil Informan Wisatawan Digital Nomad di Canggu

\begin{tabular}{|lllll|}
\hline No & Nama & $\begin{array}{l}\text { Warga } \\
\text { Negara }\end{array}$ & Umur & Pekerjaan \\
\hline 1 & Gavin & Australia & 43 & Bisnis Coach \\
\hline 2 & Guilio & Italia & 22 & $\begin{array}{l}\text { Guru Yoga/ content } \\
\text { creator }\end{array}$ \\
\hline 3 & Woojoo & Canada & 26 & Website Developer \\
\hline 4 & Luca & Denmark & 25 & Website Developer \\
\hline 5 & Keston & Australia & 30 & Freelencer \\
\hline 6 & Uga & Spanyol & 26 & Freelencer \\
\hline 7 & Alex & Belanda & 28 & Web Designer \\
\hline 8 & Miguel & Jerman & 30 & Content Creator \\
\hline 9 & Zoe & Australia & 24 & Blogger \\
\hline 10 & Monja & Jerman & 23 & Web Designer \\
\hline 11 & Melissa & Jerman & 25 & Blogger \\
\hline 12 & Mike & Jerman & 28 & Bisnis Developer \\
\hline 13 & Sascha & Jerman & 35 & $\begin{array}{l}\text { Fitness Instructor/ conten } \\
\text { creator }\end{array}$ \\
\hline 14 & Joe & Canada & 30 & Graphic Designer \\
\hline 15 & Ronan & Australia & 29 & Web Designer \\
\hline
\end{tabular}

Sumber: Penelitian 2019

Guilio menyatakan ia mengikuti program dari Nomad Academy selama 3 bulan. Nomad Academy merancang program pelatihan dengan tempat di Asia dengan durasi 1(satu) bulan di masingmasing negara seperti destinasi wisata seperti Thailand, Bali dan Malaysia. Ia merasakan Desa Canggu merupakan tempat yang nyaman sebagai seorang wisatawan digital nomad. Terdapat banyak tempat yoga terlebih ia juga merupakan seorang guru yoga (wawancara 30 April 2019). Senada dengan pernyaataan Guilio, Luca seorang website developer juga mengatakan bahwa ia sangat menikmati pantai yang di Desa Canggu dan sekitarnya untuk kegiatan berselancar. Ia juga mulai mahir menggunakan sepeda motor setelah 1 minggu tinggal di Desa Canggu (wawancara pada 25 April 2019).

Ronan, seorang wisatawan digital nomad asal Australia juga mengatakan hal senada, Bali merupakan tempat yang ideal untuk tinggal, ia merasa setiap hari adalah berlibur. Jika sudah selesai mengadakan rapat, ia dapat pergi ke pantai untuk berselancar. Kedekatan antara Indonesia dan Australia pun menjadi alasannya, dengan peraturan bebas visa yang dimiliki, ia dapat pergi kembali ke negaranya (wawancara pada 25 April 2019). Gavin menjelaskan bahwa ia berhenti dari pekerjaannya dan memutuskan untuk bekerja secara online, ia merasa lebih produktif bekerja dengan cara ini dan memilih Desa Canggu sebagai tempat yang pertama ia datangi saat di Bali dikarenakan rekomendasi dari teman-temannya. Ia tidak pernah ingin dianggap sebagai 'bule' atau panggilan bagi orang asing karena ia sangat senang hidup sebagai masyarakat lokal. Penduduk Desa Canggu yang ramah membuat ia tidak kesulitan berbaur dengan masyarakat lokal (wawancara pada 28 April 2019).

Zoe yang berprofesi sebagai blogger juga mengungkapkan bahwa Bali merupakan tempat yang instagenic, ia dapat dengan leluasa mengambil 
konten untuk blognya. Bekerja dan berwisata menjadi kesatuan yang tidak terpisahkan. Persepsi wisatawan digital nomad asal Jerman, Miguel, Monja, Mike dan Sascha mengutarakan bahwa Desa Canggu sangat lengkap mempunyai ragam pilihan restoran vegan yang mendukung gaya hidupnya. Mereka sangat mempunyai perhatian khusus terhadap pola konsumsi terlebih Sascha yang berprofesi sebagai fitness instructor dan juga content creator. Desa Canggu mempunyai café vegan yang nyaman ditambah dengan fasilitas wifi yang tersedia hampir di selurug café (wawancara pada 24 April 2019). Dari hal ini, dapat dilihat bahwa wisatawan digital nomad sangat mempunyai gaya hidup yang spesifik.

Pengalaman Uga selama tinggal di Desa Canggu, ia merasa Canggu merupakan tempat yang lengkap yang mempunyai banyak pilihan akomodasi. Ia memilih tinggal di homestay karena memiliki waktu tinggal yang panjang selama 3 bulan dan ia dapat menawar harga dengan pemilik homestay. Berbeda dengan Keston dan Alex, mereka memilih untuk tinggal di Desa Canggu dan tinggal di villa bersama agar lebih privasi (wawancara pada 26 April 2019). Melisa mempunyai pandangan bahwa Canggu merupakan tempat yang menyenangkan, setiap jalan, gang, sawah dan hal dalam kehidupan sehari-hari di Desa Canggu sangat menarik untuk difoto atau instagenic, hal ini sangat memudahkan pekerjaannya untuk mencari content bagi websitenya (wawancara pada 30 Maret 2019). Tidak hanya itu, Woojo berpendapat, bahwa Desa Canggu adalah tempat yang sempurna baginya sebagai digital nomad. Jika ia melakukannya di Hawai, biaya hidupnya akan sangat mahal, 5 kali dari Bali. Jika ia ke Sri Lanka, akses internetnya jauh lebih tidak stabil dari Bali. Destinasi yang paling mendekati
Bali sebagai destinasi digital nomad adalah Kuala Lampur, hanya saja yang kurang adalah di Kuala Lumpur tidak mempunyai pantai seperti di Bali untuk berselancar dan menikmati matahari terbenam (wawancara pada 28 April 2019).

Penulis juga mengamati persepsi wisatawan dari portal nomadlist.com mereka memberikan sejumlah ulasan mengenai pengalaman tinggal yang dirasakan di Desa Canggu yaitu "Canggu very Western. Canggu is essentially a 2-by-2 $\mathrm{km}$ resort full of expats, foreigners, nomads and tourists" (anonim pada 22 April 2019). Dari ungkapan ini wisatawan merasakan bahwa Desa Canggu sangat dipengaruhi oleh budaya barat dan sangat turistik. Jalanan dan lingkungan Desa Canggu dipenuhi oleh wisatawan, bahkan orang lokal sangat sulit untuk dilihat. Jika ada, orang lokal tersebut adalah penjaga toko, pelayan di restoran yang mana bukan asli warga lokal Desa Canggu.

Desa Canggu menjadi sangat terkesan Barat karena banyak mendapat pengaruh dari pemilik bisnis yang juga mayoritas orang barat. Penduduk lokal Desa Canggu lebih tertarik menyewakan rukonya daripada berbisnis sendiri. Tidak hanya ungakapan seperti diatas, wisatawan digital nomad juga mengatakan "Actually hard to find Balinesian food. There is a lot of overpriced, average, western, hipster food. People are incredibly kind and the Balinesian food is great when you can find it" (anonim ada 22 April 2019). Dari ungkapan wisatawan digital nomad tersebut sangat memperlihatkan bahwa Desa Canggu memang sangat di dominasi oleh café-café, restoran yang menyajikan makanan internasional. Wisatawan digital nomad merasa sangat susah untuk menemukan makanan tradisional Bali ataupun warung yang menyedikan makanan asli Indonesia. 
Wisatawan digital nomad memang mempunyai ekspektasi untuk dapat tinggal di suatu destinasi agar merasakan pengalaman tinggal seperti penduduk lokal. Menikmati makanan seperti penduduk lokal dengan harga sama seperti lokal. Penduduk Bali sangat ramah dan ia sangat merasa senang ketika dapat menemukan makanan tradisional Bali dan Indonesia.

Wisatawan digital nomad mempunyai persepsi yang buruk terhadap lalu lintas di Desa Canggu seperti ungkapan di bawah ini:

Traffic is really annoying. There's just too many loud dangerous motorbikes and scooters on too narrow roads driving too fast. And often a giant car clogging everything up in there too. Canggu will kill itself if it doesn't fix this. Canggu needs a ban on petrol bikes, only allow electric bikes, set speed limits that are enforced and promote bicycle usage. Cars should be banned altogether, it's just too small for it (anonim pada 1 Maret 2019). Dari pernyataan diatas, anonim menyebutkan bahwa lalu lintas sangat menyebalkan. Terlalu banyak sepeda motor yang berbahaya di jalanan yang sempit dan mengendarainnya dengan kecepatan tinggi. Banyak mobil yang besar juga jatuh terjungkal ke sawah di sepanjang Canggu short cut Pantai Berawa menuju Canggu. Canggu seharusnya menentang untuk sepeda motor dan hanya membolehkan sepeda elektrik dengan kecepatan yang terbatas dan mendorong untuk penggunaan sepeda. Mobil juga seharusnya dilarang untuk memasuki jalan di Canggu karena jalananya terlalu sempit.

$$
\text { Hidup di Desa Canggu }
$$

mengharuskan wisatawan dapat mengendarai sepeda motor. Kurangnya fasilitas trotoar atau fasilitas bagi pedestrian dan berjalan di samping jalan raya sangat dirasa berbahaya. Jika wisatawan mengendarai sepeda gayung, itu juga berarti membahayakan hidup anda sendiri. Lalu lintasnya tidak cukup aman, tetapi jika mengendarai motor dengan kecepatan 30km/jam kamu akan baik-baik saja. Jangan coba-coba untuk minum alcohol dan berkendara karena banyak wisatawan yang sudah meninggal akibat melakukan ini.

Motorbikes are dangerous and there are so many incredibly dangerous tourists on motorbikes either showing off on overpowered bikes or not knowing what they're doing and crashing. I've been crashes and near-misses almost every day. Had someone crash into me just yesterday. Walking is impossible and incredibly dangerous. Its not worth your life to be in a place with filthy beaches, filthy streets and incredible noise pollution from clubs and made-to-beloud motorbikes (anonim pada 1 Maret 2019).

Pernyataan diatas mengungkapkan bahwa sepeda motor sangat berbahaya dan disini juga banyak sekali wisatawan yang mengendarai sepeda motor dan bahkan mengendarainya dengan kecepatan tinggi dan tidak tahu apa yang mereka lakukan sehingga terjadi kecelakaan. Berjalan kaki menjadi hal sangatlah tidak mungkin dilakukan dan berbahaya. Tidak sepadan dengan hidup anda untuk berada di tempat dengan pantai-pantai yang kotor, jalan-jalan yang kotor dan polusi suara yang luar biasa dari klub dan sepeda motor yang keras.

Wisatawan digital nomad tidak hanya memberi persepsi yang buruk terhadap lalu lintas akan tetapi juga keamanan di Desa Canggu seperti salah satu pernyataan dibawah ini "Watch out for the bag snatchers at night, it never happened to me but I've heard some stories. Better to just wear a backpack, because they won't try to snatch that" (anonim pada 1 November 2018). Desa Canggu memang masih relatif aman bagi 
wisatawan, jarang terjadi tindak kriminal, akan tetapi yang terjadi kini mulai rawan dengan tindak kriminal yaitu tindak pencopetan.

Desa Canggu memang masih mempunyai beberapa tempat yang belum diterangi oleh penerangan jalan yang memadai dan sangat rentan terjadi tindak kriminal. Dari pernyataan beberapa persepsi wisatawan digital nomad terkait implikasi kondisi lalu lintas dan keamanan tentu saja memberi ketidaknyamanan dan rasa ketidakamanan bagi wisatawan tersebut. Hal tersebut dapat menyebabkan celaka bagi wisatawan sendiri dan warga lokal yang sering berlalu lintas. Tidak hanya itu, jika hal ini tidak diantisipasi dengan langkah yang tepat, ulasan-ulasan yang di unggah oleh para wisatawan digital nomad ini dapat memberikan citra negatif bagi Desa Canggu dan terlebih tersebut.

Dari beberapa persepsi yang buruk yang diungkapkan oleh sejumlah wisatwan nomad, juga terdapat wisatawan digital nomad yang mengatakan bahwa Desa Canggu merupakan tempat yang paling ideal di seluruh kawasan Asia Tenggara untuk bersantai dan bekerja. "Canggu is the best amongst other SE Asian area for chilling and working remotely" (anonim pada 1 November 2018). "Desa Canggu adalah tempat yang bagus untuk bekerja secara remote, poin yang bagus adalah murah dan makanan yang sehat dan tidur di tempat yang bagus. Jika wisatawan bersikap yang baik dengan orang Bali dan mayoritas orang yang tinggal di Desa Canggu, mereka akan berlaku yang baik juga dengan mereka. Wisatawan digital nomad dapat berselancar, mendaki, dan mengerdarai sepeda motor di tengah persawahan yang cantik. Menemukan kedamaian dan sebagai contohnya keinginan diri untuk bermeditasi atau berselancar.
Sejak 2016 dan seterusnya, setiap tahun semakin banyak wisatawan digital nomad mulai mengenal Desa Canggu. Pada akhir 2017, itu menjadi sangat populer di kalangan pengembara sehingga untuk pertama kalinya Dojo harus menolak keanggotaan baru. Pada saat yang sama, itu mulai menjadi hotspot untuk instagrammers, yang akan menyewa villa mewah dengan flamingo mengapung dan memotret. Pada gilirannya, ini mulai menarik lebih banyak wisatawan dan sekarang telah menjadikan Desa Canggu tempat paling populer di Bali untuk wisatawan digital nomad.

\section{SIMPULAN}

Dari identifikasi produk 4A yang menunjang kebutuhan wisatawan digital nomad dapat disimpulkan Desa Canggu sudah memenuhi pada aspek atraksi, amenitas. Hal ini mendapat respon yang sangat bagus dari pelaku dunia usaha, mereka sangat gesit untuk mengantisipasi keperluan dari kelompok wisatawan ini. Masih terdapat kekurangan pada aspek ansilari akan tetapi masih memiliki kelemahan pada aspek aksibilitas. Dari sejumlah pernyataan diatas tentunya ada beberapa hal yang patut dibenahi jika Bali dan Desa Canggu khususnya ingin tetap eksis menjadi destinasi utama wisatawan digital nomad. Adapun hal tersebut yaitu faktor lalu lintas, keamanaan. Faktor tersebut menjadi bahan masukan bagi pemerintah daerah untuk terus berbenah dalam mengembangkan pariwisata.

Perlu adanya kebijakan pengembangan pariwisata ke arah nomadic tourism khususnya yang berbasis digital. Desa Canggu sudah menjadi ikon dari wisatawan digital nomad yang semestinya dapat diberdayakan dan dikembangan bersama dengan teknologi yang lebih canggih 
sehingga Desa Canggu mempunyai brandingnya yang khas. Untuk penelitian selanjutnya dapat diteliti terkait dampak kehadiran digital nomad dari segi ekonomi, sosial dan budaya.

\section{DAFTAR PUSTAKA}

\section{$\underline{\text { Buku }}$}

Creswell, John W. 2010. Research Design Pendekatan Kualitatif, Kuantitatif, dan Mixed, Yogyakarta: Pustaka Pelajar.

Jennings, G. (2001). Tourism Research. 1st ed. Melbourne: Wiley.

Sugiyono. (2001). Metode Penelitian. Bandung: CV Alfa Beta.

Sugiyono (2015). Metode
Kombinasi $\begin{gathered}\text { Penelitian } \\ \text { Bandung: Alfabeta. }\end{gathered}$

\section{$\underline{\text { Jurnal/Proceeding/Skirpsi/Tesis/Disertasi }}$}

Haking, J. (2017). Digital Nomad Lifestyle A Field Study in Bali. KTH Royal Institute of Technology School of Industrial Engineering and Management. Stocholm: Sweden.

Kannisto, P. (2014). Global Nomads. Challenges of Mobility in the Sedentary World. Tilburg:Tilburg University.

Kaplan, C. (1996). Questions of travel: Postmodern discourse of displacement. Durham: Duke University Press.

Müller, A. (2016). The digital nomad: Buzzword or research category? Transnational Social Review: A Social Work Journal, 6(3), 344-348.

Reichenberger, I., (2017). Digital nomads-a quest for holistic freedom in work and leisure. Annals of Leisure Research, pp.1-17.

Urry, J. (2000). Sociology beyond societies: mobilities for the twenty-first century. London; New York: Routledge.

\section{Sumber Online}

Nomadlist. (2019). Canggu. [online] Diakses dari https://nomadlist.com/canggu [Diakses pada 25 Maret 2019]

Nomad Academy. (2019). [online] Diakses dari https://www.nomad.academy/ [Diakeses pada 25 Maret 2019]

Nomad. (2019). [online] Diakses dari https://www.oxfordlearnersdictiona ries.com/definition/english/nomad Diakses pada Desember 14, 2019 